\title{
EDUCAÇÃO AMBIENTAL E A QUÍMICA LICENCIATURA: AS CONCEPÇÕES DE PROFESSORES
}

\author{
Paola Alves da Silveira de Vasconcellos ${ }^{1}$
}

1Universidade Federal de Santa Maria - UFSM. paolaqmc@bol.com.br

http://dx.doi.org/10.5902/223613087811

\section{RESUMO}

Este trabalho apresenta os dados obtidos em um estudo de monografia que foi apresentada e desenvolvida no Programa de Pós-graduação em Educação Ambiental, nível de especialização do Centro de Ciências Rurais da Universidade Federal de Santa Maria, para a Linha de Educação, Sociedade e Cultura. Desenvolveu-se este estudo com o intuito de compreender qual o espaço e os significados da Educação Ambiental para um grupo de quatro professores do Curso de Química Licenciatura Plena da UFSM. Justificou-se pela necessidade de analisar a inserção da Educação Ambiental na concepção dos professores, estimulando desta forma novas percepções e reflexões sobre esse trabalho no Curso de Química. A metodologia utilizada neste estudo de monografia seguiu uma abordagem qualitativa, ou seja, privilegia os aspectos conscienciais, subjetivos dos professores participantes desta pesquisa Um dos instrumentos usados para realizar a coleta de dados foi o questionário, que teve como objetivo registrar as representações e percepções dos docentes a respeito da Educação Ambiental. A análise dos dados revelou que estes profissionais, quando indagam sobre o papel que desempenham na sociedade, enquanto pessoas conscientizadoras e formadoras de novas mentalidades preocupam-se com os aspectos socioculturais que constituem o estudante/cidadão que faz parte do Curso de Química.

Palavras-chave: Educação Ambiental; Ensino Superior; Licenciatura em Química.

\section{ABSTRACT}

This study presents data obtained in a study that monograph was presented and developed in the Post-graduate Program of Environmental Education, an Specialization Program of the Rural Sciences Centre in Federal University of Santa Maria, of the research line Education, Society and Culture. Such study was developed in order to understand the scope and meanings of Environmental Education for professors of the Chemistry Teaching Course in UFSM. The justification to develop such study was the need to analyse the insertion of Environmental Education in the conception of professors, therefore stimulating new perceptions and reflections on such theme in the Course. The method employed followed a qualitative approach, that is, it privileged the conscious and subjective aspects of the professors who participated on the research. One of the instruments used to perform the data collection was the questionnaire, aiming to register the representations and perceptions of the professors concerning Environmental Education. Analysis of data revealed that these professionals, when asked about their role in society as educators of conscientiousness and new ways of thinking, worry about the social and cultural aspects that constitute the undegraduate student/citizen who is enrolled on Chemistry Course.

Keywords: Environmental Education; Undergraduate Studies; Chemistry Teaching Course. 


\section{INTRODUÇÃO}

A Educação Ambiental é um processo que consiste em proporcionar as pessoas uma compreensão crítica e global do ambiente para elucidar valores, desenvolver atitudes, que lhes permitam adotar uma posição consciente e participativa a respeito das questões relacionadas com a conservação e a adequada utilização dos recursos naturais para melhoria da qualidade de vida e a eliminação da pobreza extrema e do consumismo desenfreado. A Educação Ambiental, dentre seus objetivos, invoca a conscientização, o desenvolvimento de habilidades e capacidades como instrumento de avaliação e participação dos indivíduos na sociedade organizada; podendo constituir-se uma opção para a transformação da realidade contemporânea, onde a tecnologia acelerou os processos de produção e consequentemente a magnitude dos problemas ambientais.

A degradação ambiental, o risco de colapso ecológico e o avanço da desigualdade e da pobreza são sinais eloquentes da crise do mundo globalizado. A sustentabilidade é o significante de uma falha fundamental na história da humanidade; crise de civilização que alcança seu momento culminante na modernidade, mas cujas origens remetem à concepção do mundo que serve de base à civilização ocidental. A sustentabilidade é o tema do nosso tempo, do final do século XX e início do século XXI, da transição da modernidade truncada e inacabada para uma pósmodernidade incerta, marcada pela diferença, pela diversidade, pela democracia e pela autonomia.

O discurso do desenvolvimento sustentável foi sendo legitimado, oficializado e difundido amplamente com base na Conferência das Nações Unidas sobre o Meio Ambiente e o Desenvolvimento, celebrada no Rio de Janeiro, em 1992. Mas, a consciência ambiental surgiu antes, como por exemplo, o livro "Primavera Silenciosa" de Rachel Carson, publicado em 1962, esta foi a primeira obra a detalhar os efeitos adversos da utilização dos pesticidas e inseticidas químicos sintéticos, iniciando o debate acerca das implicações da atividade humana sobre o ambiente e o custo ambiental dessa contaminação para a sociedade humana. A autora advertia para o fato de que a utilização de produtos químicos para controlar pragas e doenças estava interferindo com as defesas naturais do próprio ambiente natural. Com a publicação de "Primavera Silenciosa" o debate público sobre agrotóxicos continuou através dos anos 60 e algumas das substâncias listadas pela autora foram proibidas ou sofreram restrições.

Essa consciência ambiental se expandiu nos anos 70, depois da Conferência das Nações Unidas sobre o Meio Ambiente Humano, celebrada em Estocolmo, em 1972. A justificativa principal deve-se ao agravamento dos problemas ambientais e a necessidade dos processos educativos a assumirem essa perspectiva formativa em todos os cursos do ensino superior. Nestes momentos citados acima é que foram assinalados os limites da racionalidade econômica e os desafios da degradação ambiental ao projeto civilizatório da modernidade. Assim, a degradação ambiental se manifesta como sintoma de uma crise de civilização, marcada pelo modelo de modernidade regido pelo predomínio do desenvolvimento da razão tecnológica sobre a organização da natureza.

A questão ambiental deixou de ser uma preocupação restrita a alguns profissionais tradicionalmente vistos como responsáveis por problemas dessa ordem. Atualmente esse tema envolve todos, uma vez que cada um de nós está sujeito aos efeitos dos problemas ambientais, tanto regional quanto globalmente. Isto significa afirmar que a referida temática transcende o 
envolvimento apenas de biólogos, de geógrafos ou de ecologistas, mas estende-se a todos os cidadãos.

Assim, os conhecimentos e métodos necessários para compreender e resolver uma problemática ambiental depende das condições geográficas, ecológicas, políticas, econômicas e culturais que constituem o entorno no qual se inserem as universidades para formar profissionais competentes.

A inclusão do saber ambiental na formação profissional requer a elaboração de novos currículos de curso, carreiras e especialidades. A formação do saber ambiental, sob uma visão crítica e prospectiva, não alcançou uma maturidade suficiente para permear os paradigmas científicos e as estruturas acadêmicas dominantes das universidades.

O desafio da problemática ambiental e da busca do desenvolvimento sustentável surge como um novo desafio social incompreensível conceitual e praticamente por uma instituição com uma estrutura fragmentada, que, entretanto, afirma-se dizendo que a sua legitimidade social apóia-se nessa instituição privilegiadamente, onde se podem construir e incubar as possíveis soluções aos dilemas socioambientais. Não é arriscado afirmar que diante da complexidade da multidimensionalidade ambiental, que é ao mesmo tempo conceitual, teórica, pedagógica, institucional e existencial, a educação, e especificamente a educação superior, tem diante de si um dos desafios potencialmente mais revolucionários para as próximas décadas: um desafio que deve levar ao questionamento integral da instituição, nos âmbitos destacados anteriormente, para torná-la viável e sustentável num cenário futuro de profundas mudanças de toda ordem.

\section{EDUCAÇÃO AMBIENTAL E O ENSINO SUPERIOR}

Desde os clássicos e os teóricos da educação superior afirmou-se que a educação em geral, e a educação universitária em particular, têm sentido na medida em que formam conhecimentos, habilidades e valores orientados a colaborar na compreensão e solução dos problemas da sociedade na qual estão imersas. Além de serem um veículo de mobilidade social para aqueles que têm acesso a esse âmbito do social.

Com a emergência da crise ambiental, o processo educacional orientou um processo de conscientização para regularem condutas sociais que evitem efeitos negativos sobre o ambiente e criar habilidades técnicas para resolver problemas ambientais. Desde a Conferência de Estocolmo sobre o Meio Ambiente Humano, celebrada em 1972, a Educação Ambiental foi apresentada como um meio prioritário de alcançar os fins de um desenvolvimento sustentável. Depois, a Conferência Intergovernamental de Educação Ambiental, celebrada em Tbilisi, em 1977, estabeleceu os princípios gerais que deviam orientar os esforços de uma educação relativa ao ambiente. Este processo de formação e conscientização

não só deve sensibilizar, mas modificar as atitudes e fazer adquirir os novos enfoques e conhecimento que a interdisciplinaridade exige, isto é, a cooperação entre as disciplinas tradicionais indispensáveis para apreender a complexidade dos problemas do ambiente e para a formulação de suas soluções (Unesco, 1980).

A necessidade de compreender a complexidade da problemática ambiental, bem como os múltiplos processos que a caracterizam, provocou um questionamento da fragmentação e da compartimentalização de um saber disciplinar, incapaz de explicitar e resolver esta problemática. Mas a retotalização do saber que a problemática ambiental requer não é a soma nem a integração 
dos conhecimentos disciplinares herdados. A interdisciplinaridade e transdisciplinaridade que o saber ambiental exige é problematizar o conhecimento, mas sem desconhecer a especificidade das diferentes ciências historicamente constituídas, ideologicamente legitimadas e socialmente institucionalizadas.

A inserção da Educação Ambiental no currículo formal do ensino superior nas graduações que atuam na área ambiental, em especial nas licenciaturas tem contribuído para a sustentação da vertente ecológica em relação ao meio ambiente e a conservação dos recursos naturais.

Para Mininni (1997), a vertente Ecológico-Preservacionista considera que o centro de desarmonia homem-natureza reside na maneira do homem relacionar-se individualmente com o meio ambiente e atribui à Educação Ambiental, a responsabilidade para mudar essa relação, centrando-se nas mudanças de comportamento individual dos homens por meio da incorporação de novos valores. Por conseguinte, as relações homem-natureza se transformariam, solucionando, de maneira permanente e incessante, os problemas ambientais, revertendo as tendências atuais. No que refere aos aspectos cognitivos, estes se reduzem à aquisição de conhecimentos da ecologia e biologia. Na verdade, a Educação Ambiental se confunde com o ensino da ecologia, efetuando-se assim, uma série de reducionismos.

O conceito de ambiente vem evoluindo de uma perspectiva naturalista ou ecologista para a incorporação dos processos sociais que determinam a problemática ambiental. A pesar desta evolução conceitual, nos programas de Educação Ambiental predominou uma visão ecologista. Neste sentido, incorporaram-se conceitos básicos de ecologia, como também de técnicas de avaliação e controle de impactos ambientais nas carreiras tradicionais:

Se é verdade que os aspectos biológicos e físicos constituem a base natural do ambiente humano, as dimensões socioculturais e econômicas definem as orientações e os instrumentos conceituais e técnicos que permitem ao homem compreender e utilizar melhor os recursos da biosfera para a satisfação de suas necessidades (Unesco, 1980).

A própria visão reducionista dos cursos de licenciaturas em relação ao meio ambiente, não relacionam o "modo de vida" do indivíduo com os problemas ambientais onde ele se encontra e remetem o licenciado que, em caso de dúvida, procurem um especialista na área ambiental. Mas isso vem sendo vencido com o esforço de alguns professores das ciências da vida, ciências exatas e ciências humanas. Nas ciências exatas, apesar de alguma resistência, já há um desejo consciente, da parte de alguns professores, de formar profissionais atualizados e compromissados com a causa ambiental.

Morin (1999) nos diz que precisamos avançar para além do pensamento reducionista e do pensamento holista, pois os dois são mutilantes. O primeiro mutila a visão do todo em prol da visão das partes, o segundo mutila a visão das partes em prol da visão do todo. Este autor cunha um sentido paradigmático para a complexidade: "a complexidade não é um conceito, mas uma forma de enxergamos a realidade", pois se apresenta como uma nova compreensão dos desafios que precisamos enfrentar no momento da ação devido ao conhecimento incompleto que temos da realidade. Estes desafios não são pequenos, pois aprendemos e ensinamos separando. Entre tantas outras disjunções separamos a razão e o sentimento, o sujeito e o objeto, o social e o natural, o indivíduo do coletivo.

Nas investigações de como conceber a problemática ambiental e as propostas de Educação ambiental, Mininni (1997) nos diz que na vertente Sócio-Ambiental, defende-se uma educação de caráter permanente, preocupada não só com o aqui e agora, mas também com o futuro. Preocupa-se, também, em elaborar valores éticos, porém, centra-se nos conhecimentos 
historicamente produzidos pela humanidade. Visa, por conseguinte, a plena realização do homem, em todos os seus aspectos e a sua sobrevivência como espécie. Nesta vertente, assim como na outra, propõe-se uma educação voltada para a preservação e conservação da natureza. Todavia, traz como preocupação central, a análise econômico-social dos problemas ambientais.

$\mathrm{Na}$ Educação Ambiental brasileira está surgindo uma grande diversidade de vertentes contrapondo uma Educação Ambiental reducionista e distanciada das questões sociais, como por exemplo, a Educação Ambiental Crítica e a Transformadora. A Educação Ambiental Crítica constitui-se, no campo educativo, no encontro da Educação Ambiental com o pensamento crítico:

\begin{abstract}
A educação crítica tem suas raízes nos ideais democráticos e emancipatórios do pensamento crítico aplicados à educação. No Brasil, estes ideais foram constitutivos da educação popular que rompe com uma visão de educação tecnicista, difusora e repassadora de conhecimentos, convocando a educação a assumir a mediação na construção social de conhecimentos implicados na vida do sujeito (CARVALHO, 2004, p.18).
\end{abstract}

Partindo para as ações pedagógicas, Carvalho acredita que a Educação Ambiental Crítica tem como prática educativa à formação do sujeito humano enquanto ser individual e social, historicamente situada. Porém alerta que não é uma ação educativa centralizada exclusivamente no indivíduo como também não se perde no coletivo abstrato:

Na perspectiva de uma educação ambiental crítica, a formação incide sobre as relações indivíduo-sociedade e, neste sentido, indivíduo e coletividade só fazem sentido se pensados em relação. As pessoas se constituem em relação ao mundo em que vivem com os outros. Na educação ambiental crítica esta tomada de posição de responsabilidade pelo mundo supõe a responsabilidade consigo próprio, com os outros e com o ambiente, sem dicotomizar e/ou hierarquizar estas dimensões da ação humana (CARVALHO, 2004, p.20).

A Educação Ambiental Transformadora constitui-se no Brasil nos anos 80 pela aproximação de educadores, principalmente os da educação popular e instituições públicas de educação, junto aos militares dos movimentos sociais e ambientalistas com foco na transformação societária e no questionamento radical aos padrões industriais e de consumo consolidados no capitalismo (Loureiro, 2004). A finalidade primordial desta educação é revolucionar os indivíduos em suas subjetividades e práticas nas estruturas social-naturais existentes. Loureiro (2004) caracteriza essa educação Transformadora como uma educação permanente, cotidiana e coletiva pelo qual agimos e refletimos, transformando a realidade de vida. A metodologia da Educação Ambiental Transformadora está na participação e no exercício da cidadania:

[...] princípios para a definição democrática de quais são as relações adequadas ou vistas como sustentáveis à vida planetária em cada contexto histórico. [...] Educar para transformar significa romper com as práticas sociais contrárias ao bem estar público, à equidade e à solidariedade, estando articulada necessariamente às mudanças éticas que se fazem pertinentes (LOUREIRO, 2004, p.81).

Paulo Freire é uma das referências do pensamento crítico na educação brasileira e sua pedagogia libertária e emancipatória é uma influência destacada por Carvalho (2004) e Loureiro (2004). 
Deste modo, a Educação Ambiental deve integrar os currículos dos Programas de Graduação, principalmente de todos os cursos de licenciatura. Logo, cabe à universidade, promover articulações intra e interinstitucionais, no sentido de favorecer a formação e capacitação de profissionais competentes e preparados para produzir mudanças no perfil educacional brasileiro, em particular no que se refere à Educação Ambiental (Castro, 2000).

Uma contradição a enfrentar, no entanto, é a tendência para a Educação Ambiental se concretizar apenas como disciplina isolada, quase sempre sem status dentro da universidade.

\section{METODOLOGIA}

A pesquisa tem uma abordagem qualitativa, ou seja, possui um enfoque que privilegia os aspectos conscienciais, subjetivos dos atores (professores participantes desta pesquisa), são eles: percepções, processos de conscientização, de compreensão do contexto sociocultural, em função da realidade, da relevância dos fenômenos pelos significados que eles têm para o sujeito.

Os instrumentos usados para realizar a coleta de dados desta pesquisa qualitativa foram o questionário, com predomínio de perguntas abertas, e a análise documental. As perguntas abertas, também chamadas livres ou não limitadas, são as que permitem ao informante responder livremente, usando linguagem própria, e emitir opiniões. Possibilita investigações mais profundas e precisas. A análise é mais difícil, complexa, cansativa e demorada (Marconi e Lakatos, 1990). As perguntas abertas de um questionário devem ser poucas: entre duas e cinco interrogativas são suficientes, pois os respondentes deverão escrever suas idéias, o que exigirá deles tempo e esforço. O número limitado de perguntas obriga o investigador a um trabalho cuidadoso em extremo. Com efeito, as indagações propostas ao sujeito, além de serem claras, precisas e expressas numa linguagem natural adequada ao ambiente no qual se realiza a pesquisa, devem apontar os assuntos medulares do problema.

Segundo Triviños (1987), os questionários são meios "neutros" que adquirem vida definida quando o pesquisador os ilumina com determinada teoria.

Assim como os questionários, a análise documental requer que as descobertas tenham relevância teórica. Uma informação puramente descritiva não relacionada a outros atributos ou às características do emissor é de pequeno valor.

O questionário tem como objetivo registrar as representações e concepções dos docentes sobre a Educação Ambiental no Curso, procurando identificar os pontos e dificuldades comuns. As representações sociais equivalem a um conjunto de princípios construídos interativamente e compartilhados por diferentes grupos que através delas compreendem e transformam sua realidade (Reigota, 2007).

Antes da aplicação do questionário foi realizada uma conversa informal com os quatro professores participantes desta pesquisa sobre o assunto deste estudo: a Educação Ambiental. Estes professores são atuantes no curso de graduação de Química Licenciatura da Universidade Federal de Santa Maria.

Trivinõs (1987) salienta que o investigador, ainda que pertença à mesma área dos sujeitos que estão participando na pesquisa, enfrenta uma realidade cultural específica, desconhecida, possivelmente, para ele, e da qual precisa tomar consciência em suas características principais se deseja realizar um trabalho específico. Este penetrar nos traços essenciais de uma cultura é realizado através do processo de aculturação que pode ser consciente ou inconsciente. 


\section{RESULTADOS E DISCUSSÕES}

Encontram-se aqui a análise de três questões do questionário aplicado aos quatro docentes do Curso de Química Licenciatura, os professores foram numerados (de 1 a 4).

$\mathrm{Na}$ questão que se pede para os professores definirem a concepção de Educação Ambiental, os professores a percebem como um processo que leva a compreensão de como funciona o ambiente, incluindo a participação humana, o que considera de grande relevância, pois não se pode entender esse complexo sistema sem incluir a participação humana. E de outro modo, referem-se a um projeto conscientizador.

Um dos professores assim se expressa:

"De maneira bastante resumida eu creio que primeiramente, a educação ambiental deve levar ao conhecimento das pessoas sobre os ciclos e funcionamento da natureza e do meio ambiente como um todo, onde estas pessoas estão também inseridas a despeito de suas vontades, exercendo, portanto ações e influenciando estes ciclos, ou seja, etapa de conscientização. Posteriormente, deve despertar iniciativas individuais e coletivas de ações que efetivamente terão resultados positivos sobre o meio ambiente, independente do prazo em que estes resultados acontecerão." (Professor 2)

Um dos professores tem uma posição mais abrangente em relação à Educação Ambiental, já que para ele compreende um

"Espaço teórico e prático de pensar as relações e mediações do ser humano com o meio natural e social. A educação ambiental torna pedagógicas estas relações e reflexões." (Professor 3)

O papel do educador está sempre envolvido na tarefa reflexiva que implica provocar outras leituras da vida, novas compreensões e versões possíveis sobre o mundo e sobre nossa ação no mundo. O importante é lembrar que não há apenas uma leitura sobre dada acontecimento, seja este social ou natural:

A educação ambiental fomenta sensibilidades afetivas e capacidades cognitivas para uma leitura do mundo do ponto de vista ambiental. Dessa forma, estabelece-se como mediação para múltiplas compreensões da experiência do indivíduo e dos coletivos sociais em suas relações com o ambiente. (CARVALHO, 2006, p.79).

Outro professor descreve sobre a Educação Ambiental:

“O assunto é complexo, mas entendo que começa pela conscientização das pessoas, que é o passo mais importante. Sem conscientização não adianta querer que as pessoas sigam aquilo que a gente pensa e que acha que é certo. A conscientização é mostrar para as pessoas que se trata de um assunto que ela também irá usufruir e que terá benefícios. Quando as pessoas enxergam e compreendem que se trata de uma coisa importante para elas, com certeza, começaram a agir do nosso lado." (Professor 1)

Morin (1980) entende a complexidade como um tipo de pensamento que não separa, mas une e busca as relações necessárias e interdependentes de todos os aspectos da vida humana. Trata-se de um pensamento que integra os diferentes modos de pensar, opondo-se aos mecanismos reducionistas, simplificadores e disjuntivos. Esse pensamento considera todas as 
influências recebidas, internas e externas, e ainda enfrenta a incerteza e a contradição, sem deixar de conviver com a solidariedade dos fenômenos existentes. Enfatiza o problema e não uma solução linear.

A complexidade agrega novos conceitos para a compreensão da realidade socioambiental, interpretando-a como uma relação intrincada, permanente e recíproca entre elementos das sociedades humanas e dos elementos da natureza.

Para trabalhar a complexidade implica fazer ver as conexões entre campos que normalmente se apresentavam como separados. Leff cita em seu livro "A complexidade ambiental":

O docente deve desenvolver as habilidades e conhecer as técnicas específicas de trabalho didático que permitam alcançar o domínio ou a compreensão de algum campo e ao mesmo tempo detectar a rede de inter-relações em que se encontra inscrito ao mesmo. $(2003$, p.226)

A distinção entre o que os professores entendem por Educação Ambiental apresenta-se no instante em que se avalia o espaço desta nas disciplinas. Os professores de forma geral contam que há o espaço e descrevem atividades que, embora apresentando variações de conteúdo e metodologia, se referem mais a uma Educação Ambiental do tipo preservacionista.

Um professor conta a atividade proposta nas suas aulas de laboratório:

\begin{abstract}
"Através da coleta, armazenamento e tratamento de maneira adequada, de todos os tipos de resíduos químicos que são gerados durante as próprias aulas práticas (atividade realizada pelos alunos). Análise qualitativa e quantitativa de vários analitos como chumbo, ferro, alumínio, zinco em amostras ambientais como solo, água, folhas, embalagens plásticas, etc." (Professor 2)
\end{abstract}

Já outro professor descreve que:

“É impossível refletir sobre a História da Química e seus processos de construção do conhecimento sem pensar sobre a evolução histórica da relação do ser humano e o mundo natural e social." (Professor 3)

No momento em que se pede para o professor fornecer sugestões para a inserção da Educação Ambiental no Curso, percebe-se que ainda existe entre os professores uma visão mais conservadora de Educação Ambiental.

Um professor escreve:

"Vou sugerir que se coloque uma disciplina, de Educação Ambiental, nem que seja como DCG." (Professor 1)

Outro escreve:

“Através de disciplinas complementares de graduação (DCG)." (Professor 4)

Embora as respostas revelem visões preservacionistas e conservadoras, entende-se que estes profissionais, quando analisam o papel que os profissionais irão desempenhar na sociedade, manifestam-se como pessoas conscientizadoras e formadoras de novas mentalidades 
preocupando-se com os aspectos sociais e culturais que constituem o estudante, cidadão que está presente no Curso de Química.

Essa questão sobre a inserção da Educação Ambiental na formação inicial, evitando incorrer no risco do reducionismo, com a criação de uma disciplina específica, faz com que surja esta discussão sobre a criação ou não de uma disciplina específica para os cursos de formação de professores (as). Uma vez que se tornou uma questão paradoxal: por um lado, aqueles e aquelas que concordavam que uma disciplina específica garantiria o locus da formação; por outro, aqueles e aquelas que pensavam que uma disciplina não contribuiria por si só para uma mudança de paradigma e, talvez, reafirmasse a concepção de um paradigma dominante de currículo que fraciona, divide e aprisiona os conhecimentos em gaiolas.

Talvez essa proposta possa ser considerada uma estratégia emergencial para efetivação da Educação Ambiental, mesmo atingindo somente os primeiros níveis da transversalidade, da inter e da transdisciplinaridade. As instituições de Ensino Superior é que são as grandes responsáveis pelos processos de formação inicial, e um investimento efetivo na formação continuada, como a grande e real possibilidade dessa inserção.

\section{CONSIDERAÇÕES FINAIS}

A questão ambiental é uma problemática social que transcende a incumbência das universidades, a formação superior e a formação continuada de profissionais, para adaptar-se às mudanças globais do nosso tempo. O saber ambiental questiona todas as disciplinas e todos os níveis do sistema educacional. A Educação Ambiental exige ainda, novas atitudes dos professores e alunos, novas relações sociais para a produção do saber ambiental, novas formas de inscrição da subjetividade nas práticas pedagógicas.

O saber ambiental não se forma nem se esgota nos laboratórios e nas aulas universitárias. É um saber que se constitui na aplicação das ciências aos problemas ambientais, num diálogo entre os conhecimentos acadêmicos e os saberes populares.

Através deste estudo pode-se compreender que há um espaço da Educação Ambiental que pode ser ampliado no Curso de Química Licenciatura da UFSM. Em relação ao significado da Educação Ambiental no Curso, concluiu-se que para alguns professores ela tem um sentido restrito e para outros, há uma acepção mais ampla. E também pode-se perceber que houve uma reflexão sobre os problemas ambientais relacionados ao exercício profissional do licenciado em Química. Ao mesmo tempo, proporcionando uma maior conscientização diante da necessidade da Educação Ambiental na formação universitária ainda que, esta educação não esteja integralmente inserida no currículo do Curso.

Portanto, os objetivos da Educação Ambiental não serão alcançados com ações isoladas de ensino ou com a incorporação de uma matéria de caráter integrador - a ecologia - dentro dos programas existentes. A Educação Ambiental exige a criação de um saber ambiental e sua assimilação transformadora às disciplinas que deverão gerar os conteúdos concretos das novas temáticas ambientais, vislumbrando esta educação como um elemento central para a construção de uma sociedade mais justa, ecologicamente sustentável e igualitária. 


\section{REFERÊNCIAS BIBLIOGRÁFICAS}

CARVALHO, I. C. M. Educação Ambiental Crítica: nomes e endereçamentos da educação. In: LAYRARGUES, P. P. (coord.). Identidades da educação ambiental brasileira. Brasília: Ministério do Meio Ambiente, 2004. 156p.

Educação ambiental: a formação do sujeito ecológico. 2. ed

São Paulo: Cortez, 2006.

CASTRO, R. S. de; LOUREIRO, C. F. B.; LAYRARGUES, P. P. (orgs.). Sociedade e Meio Ambiente: a educação ambiental em debate. São Paulo: Cortez, 2000.

LEFF, E. (coord.): tradução de Eliete Wolff. A Complexidade ambiental. São Paulo: Cortez, 2003. 342 p.

LOUREIRO, C. F. B. Educação Ambiental Transformadora. In: LAYRARGUES, P. P. (coord.). Identidades da educação ambiental brasileira. Brasília: Ministério do Meio Ambiente, 2004. 156p.

MARCONI, M. de A.; LAKATOS, E. M. Técnicas de Pesquisa: planejamento e execução de pesquisas, amostragem e técnicas de pesquisa, elaboração, análise e interpretação de dados. 2. ed. São Paulo: Atlas, 1990.

MININNI, M. N. “Amazônia: Uma proposta interdisciplinar de educação ambiental”. In: SGUAREZZI, N de O. Análise de um programa de formação de recursos humanos em educação ambiental. Instituto Brasileiro do Meio Ambiente e dos Recursos Naturais Renováveis (IBAMA), 1997.

MORIN E. Por uma Reforma do Pensamento. In: PENA VEGA (org.). O pensar Complexo. Rio de Janeiro: Garamond, 1999.

REIGOTA, M. Meio Ambiente e representação social. 7. ed. São Paulo: Cortez, 2007. (Coleção Questões da Nossa Época; v. 41).

TRIVIÑOS, A. N. S. Introdução à pesquisa em ciências sociais: a pesquisa qualitativa em educação. São Paulo: Atlas, 1987.

VASCONCELLOS, P. A. da S. de, Educação Ambiental no Curso de Licenciatura em Química: as concepções dos professores. 2010. 43p. Monografia (Especialização) Programa de Pós-Graduação de Educação Ambiental, Universidade Federal de Santa Maria, Santa Maria, RS.

UNESCO. Environmental Education. The main guidance from the Tbilisi Conference. Paris: Unesco, 1980. 